\title{
Septin4 promotes cell death in human colon cancer cells by interacting with BAX
}

\author{
Xin Zhao ${ }^{1 *}$, Hao Feng ${ }^{2 *}$, Yang Wang 3 , Yanmei $\mathrm{Wu}^{3}$, Qiqiang Guo ${ }^{1}$, Yanling Feng ${ }^{1}$, Mengtao Ma1, Wendong \\ Guo $^{1}$, Xiaoyu Song ${ }^{1}$, Ying Zhang ${ }^{\natural}$, Shuai Han ${ }^{5 凶}$, Liu Cao ${ }^{1 凶}$ \\ 1. Key Laboratory of Medical Cell Biology, Ministry of Education; Institute of Translational Medicine, Collegeof Medical Science, China Medical University; \\ Liaoning Province, Collaborative Innovation Center of Aging Related Disease Diagnosis and Treatment and Prevention, Shenyang, Liaoning Province, \\ China \\ 2. Department of Ophthalmology, The First Hospital of China Medical University, Shenyang, Liaoning Province, China \\ 3. Panjin Liaohe Oilfield Gem Flower Hospital, Panjin, Liaoning Province, China \\ 4. Department of Cardiology, the First Hospital of China Medical University, Shenyang, Liaoning, China. \\ 5. Department of Neurosurgery, the First Hospital of China Medical University, Shenyang Liaoning Province, China \\ *These authors contributed equally to this work.
}

$\triangle$ Corresponding author: Liu Cao, Institute of Translational Medicine, China Medical University, No.77 Puhe Road, Shenyang North New Area, Shenyang, Liaoning Province, 110122, China. Tel: +86 024 31939630; Fax: +86 024 31939630; E-mail: lcao@cmu.edu.cn; Shuai Han, Department of Neurosurgery, the First Hospital of China Medical University, Shenyang Liaoning Province, China. Tel: +86 1384056977; E-mail: hanshuai537197@sina.com. Ying Zhang, Department of Cardiology, The First Hospital of China medical University, Shenyang, Liaoning Province, 110122, China. Tel: +86 13224130039; E-mail: yzhang02@cmu.edu.cn

(c) The author(s). This is an open access article distributed under the terms of the Creative Commons Attribution License (https://creativecommons.org/licenses/by/4.0/). See http://ivyspring.com/terms for full terms and conditions.

Received: 2020.01.31; Accepted: 2020.04.01; Published: 2020.04.07

\begin{abstract}
Septin4 is a tumor suppressor protein that promotes cell programmed death in various cell types through specifically antagonizing XIAP ( $X$ linked inhibitor of apoptosis), little is known its other novel binding partner and role in colorectal cancer. In this study, we found that Septin4 significantly expressed lower in human colon cancer when compared to peri-tumor benign cells, and its low expression was significantly associated with worse prognostic outcomes. Furthermore, Septin4 participated in DOX-induced colon cancer cell death in vitro. Septin4-overexpressing colon cancer cells displayed augmented apoptotic cell death and ROS production. Additionally, Septin4-knockdown cells revealed a resistance of DOX-induced cell death and reduced ROS production. Importantly, we first identified that BAX is a novel Septin4 binding partner and the interaction is enhanced under DOX treatment. Finally, Septin4-knockdown promoted colon cells growth in vivo. These observations suggest that Septin 4 as an essential molecule contribute to the occurrence and development of human colon cancer and provide new technical approaches for targeted treatment of this disease.
\end{abstract}

Key words: Septin4, BAX, Colon Cancer, apoptosis

\section{Introduction}

Colorectal cancer (CRC) is the third most common malignant tumor in the world after lung cancer and gastric cancer and is also the second most lethal tumor [1]. Though potential risk factors can be changed, somatic gene mutations and epigenetic abnormalities can induce tumor occurrence [2]. In the past few decades, our understanding of the epidemiology, etiology, molecular biology, and clinical aspects of CRC has greatly advanced [3]. Nevertheless, 1.8 million new CRC cases are reported every year worldwide. Diagnosis is usually made in the later clinical stages of this disease, and thus, approximately 900,000 people die of this malignancy each year. In relatively underdeveloped countries, the existing screening methods and available medical means are not enough to halt the rising trend of these rates [3]. Therefore, to prevent the occurrence and development of $\mathrm{CRC}$, and to provide effective strategies for clinical treatment, it is essential to understand the pathogenesis and the molecular mechanism of this disease.

Apoptosis has critical roles in organ development, tissue homeostasis, and defense mechanisms that can remove useless or potentially 
cancerous cells $[4,5]$. Decreased apoptosis can lead to a variety of pathological processes, including cancer [6], and caspase activation is the ultimate marker of apoptosis. Because their activation can lead to a series of serious consequences related to apoptosis, caspases are precisely regulated by different positive or negative regulatory factors [7]. In living cells, X-linked inhibitor of apoptosis (XIAP) can directly bind to caspases, inhibit caspase activity, and negatively regulate apoptosis [8]. Therefore, XIAP antagonistic proteins are necessary to promote cell death and maintain tissue renewal by inhibiting XIAP activity [9-11].

Septin4 is the most important XIAP antagonist proteins, located in the outer mitochondrial membrane [11-14]. When apoptosis occurs, spetin4 can translocate from the mitochondria to cytoplasm and directly bind to XIAP, thus activating caspases and leading to cell death [15, 16]. Moreover, unlike traditional tumor suppressors or oncogenes, whose loss- or gain-of-function mutations can lead to the occurrence of cancer [17], Septin4 can affect tumor occurrence through expression changes, which makes it a more universal cancer suppressor. Studies have shown that the expression of Septin4 is decreased in acute lymphoblastic leukemia, and the proportion of hematopoietic stem cells can be increased through resistance to apoptosis by knocking out Septin4[18, 19]. Recent studies further demonstrated that one of the major proteins encoded by the Septin4 gene, Sept4_i2/ARTS, is highly expressed in the intestinal stem cells (ISCs) in the niche of the crypts of Lieberkuhn. Sept4_i2/ARTS can regulate the number of ISCs in the intestinal crypt by promoting apoptosis to maintain the homeostasis and regeneration of intestinal epithelial cells [20]. With the recent in-depth study of the cell biological function of Septin4, accumulating evidence has suggested that Septin 4 is involved in the regulation of tumor cell death, proliferation, angiogenesis, and invasion, which is a marker of these molecular mechanisms [21].

The mitochondrial apoptosis pathway is regulated by Bcl-2 family members, maintaining the basic balance of cell survival and death [22]. Breaking this balance can lead to pathological proliferation of cells, such as cancer or autoimmune diseases and pathological cell death, including neurodegenerative diseases or bone marrow failure. Mitochondrial outer membrane permeability (MOMP) marks the outcome of Bcl2-family-regulated apoptosis [23]. BAX, an apoptosis-promoting protein with multiple $\mathrm{BH}$ domains, is located in the outer membrane of mitochondria and has the ability to self-assemble into homologous oligomers to decrease MOMP [24]. BAX exists in almost all cell types, including tumor cells.
The early model of apoptosis activation suggested that BAX activation is regulated by the inhibitory interaction of anti-apoptotic members on the outer mitochondrial membrane [24]. Therefore, to activate apoptosis, BAX needs to be replaced and activated by the anti-apoptotic protein complex to form homologous oligomers and trigger MOMP.

In this study, we first confirmed that Septin4 expression levels were decreased with increased colon cancer grade, and patients with high expression of Septin4 had a good prognosis. We confirmed that Septin4 can promote the apoptosis of colon cancer cells by binding to BAX. And Septin4 knockdown accelerated subcutaneous tumor growth in vivo. These findings may contribute to future research on the occurrence and development of CRC and provide new technical approaches for targeted treatment of CRC.

\section{Materials and Methods}

\section{Cell culture}

Human colon cancer cells (HCT116) were purchased from the American Type Culture Collection (ATCC, USA) and cultured in 1640 medium (HyClone, GE lifescience, UK) supplemented with $10 \%$ fetal bovine serum (FBS; Clark Bioscience, Richmond, VA), penicillin (100 units/ml), and streptomycin $(100 \mu \mathrm{g} / \mathrm{ml})$. All cells were cultured in a humidified incubator at $37^{\circ} \mathrm{C}$ with $5 \%(\mathrm{v} / \mathrm{v}) \mathrm{CO}_{2}$.

\section{Liposome transfection}

The eukaryotic expression plasmid GV141Septin4-3×Flag was purchased from Genechem Co.,Ltd. (Shanghai, China) The cells were seeded into $6 \mathrm{~cm}$ plates one day before transfection, with the confluence of the transfected cells reaching $70 \%-80 \%$ the next day. Cells were transfected with plasmids using Lipofectamine 3000 (Invitrogen, USA) according to the manufacturer's instructions. The experiments were carried out $48 \mathrm{~h}$ after transfection.

\section{Lentivirus infection}

The target fragment and packaging plasmid of human lentivirus shSeptin4 were purchased from Shanghai Genechem Co.,Ltd. (shSeptin4 target sequence 1: ccTAAAGGAAAGCATCCCATT; shSep tin4 target sequence 2: ccTAAAGGAAAGCAT CCCATT; shSeptin4 target sequence 3: cCTAAAGGAAAGCATCCCATT). Lentivirus was produced in HEK-293T cells that were transfected with shRNA-expression vector. The virus supernatant was centrifuged at $1500 \mathrm{~g}$ for $5 \mathrm{~min}$ to remove cell fragments. The supernatant was then put into a chromatography cabinet for $24 \mathrm{~h}$ and centrifuged at $1500 \mathrm{~g}$ for $20 \mathrm{~min}$ at $4{ }^{\circ} \mathrm{C}$. The virus particles were 
suspended in PBS and was added to the target cells. After $72 \mathrm{~h}$ of infection, $1 \mu \mathrm{g} / \mathrm{ml}$ puromycin was added for screening and cells were cultured for 7 days.

\section{Western blotting}

The cell precipitate was collected and washed with precooled PBS, and then centrifuged at $1000 \mathrm{~g}$ for 5 min at $4{ }^{\circ} \mathrm{C}$. Whole cells were lysed with lysis buffer containing $100 \times$ protease inhibitor and $100 \times$ PMSF and centrifuged at $13500 \mathrm{rpm}$ at $4^{\circ} \mathrm{C}$ for $20 \mathrm{~min}$. In general, $30-50 \mu \mathrm{g}$ protein was added to $6 \times$ protein loading buffer (final concentration, $1 \times$ ) and boiled for 5-10 min before being subjected to SDS-PAGE and transferred onto PVDF membranes (Merck KGaA, Darmstadt, Germany). The membranes were incubated with blocking solution (TBST $+5 \%$ BSA) at room temperature for $1 \mathrm{~h}$, then specific primary antibodies: goat polyclonal anti-Septin4 (ab166788, Abcam, UK), rabbit polyclonal anti-cleaved-caspase3 (19877-1-AP, Proteintech, USA), rabbit polyclonal anti-cleaved-PARP1 (5625S, Cell Signaling Technology, USA), rabbit polyclonal anti-BAX (50599-2-lg, Proteintech, USA), rabbit polyclonal anti-PCNA (10205-2-AP, Proteintech, USA), mouse monoclonal anti-Flag (GNI4110-FG, GNI, Japan), mouse monoclonal anti-GAPDH (10494-1-AP, Proteintech) or mouse monoclonal anti- $\beta$-actin (mAbcam 8226, Abcam, UK) were added and the blots were slowly shaken overnight at $4^{\circ} \mathrm{C}$. The membranes were washed before incubation with the relevant secondary antibody at room temperature for $1 \mathrm{~h}$. Blots were exposed to ECL luminescence reagent and images were collected using the chemiluminescence system (Tanon, TanonScience \& Technology Co., Ltd., China).

\section{Immunoprecipitation}

Cell precipitates were collected and lysed with IP lysis $(137 \mathrm{mM} \mathrm{NaCl}, 10 \mathrm{mM} \mathrm{NaF}, 50 \mathrm{mM}$ Tris $\mathrm{HCl}$ (ph 7.6), $1 \mathrm{mM}$ EDTA, $0.1 \mathrm{mM} \mathrm{Na}_{3} \mathrm{PO}_{4}, 10 \%$ glycerol, $1 \%$ $\mathrm{NP}-40$, and $1 \mathrm{mM}$ PMSF). Then $1 \mathrm{mg}$ protein supernatant was incubated with the corresponding antibody for $3 \mathrm{~h}$ at $4{ }^{\circ} \mathrm{C}$ and placed with protein $\mathrm{A} / \mathrm{G}$ beads (sc-2003, Santa Cruz, USA) for $12 \mathrm{~h}$ at $4{ }^{\circ} \mathrm{C}$. The beads were then washed three times with precooled lysate at $4{ }^{\circ} \mathrm{C}$ for $15 \mathrm{~min}$, then subjected to SDS-PAGE.

\section{Immunohistochemistry}

HCo1a180su17, a human colon cancer chip, was purchased from Outdo Biotech CO., Ltd (Shanghai, China). It contained 80 cases of cancer and adjacent tissues for which the survival information of patients was known. The colon cancer chip was treated as follows: $45^{\circ} \mathrm{C}$ for $1 \mathrm{~h}$, dried at $42{ }^{\circ} \mathrm{C}$ for $1 \mathrm{~h}, 72{ }^{\circ} \mathrm{C}$ for 3 $\mathrm{h}$, and $2 \mathrm{~h}$ at $42{ }^{\circ} \mathrm{C}$ before staining. Xylene was used for dewaxing, and an ethanol gradient of anhydrous ethanol, $90 \%, 80 \%$, and $70 \%$ ethanol was used for gradient dehydration for $5 \mathrm{~min}$ at each concentration. Then the chip was soaked in water for $5 \mathrm{~min}$, and finally in PBS. Antigen retrieval was carried out with high pressure heating in sodium citrate buffer $(\mathrm{pH}$ 6.0) for $2 \mathrm{~min}$. The chip was incubated with goat anti-Septin 4 overnight at $4{ }^{\circ} \mathrm{C}$. Finally, the chip was dehydrated in a $70 \%, 80 \%$, and $90 \%$ ethanol gradient, followed by xylene dehydration. The chip was sealed with neutral resin, dried, and stored at room temperature, before imaging by optical microscopy.

\section{CCK8 cell viability assay}

Cells were seeded in 96-well plates at a density of 3000 cells/well. After treatment, the cell culture medium was removed and replaced with $90 \mu \mathrm{L}$ serum-free 1640 medium. Cell Counting Kit-8 (CCK8, Dojindo, Japan) staining solution $(10 \mu \mathrm{L})$ was added to the cells and incubated at $37{ }^{\circ} \mathrm{C}$ for $2 \mathrm{~h}$, then absorbance at $450 \mathrm{~nm}$ was measured by Absorbance Reader (Tecan, Switzerland).

\section{DHR reactive oxygen species staining}

According to the required dosage, DHR probes (Sigma-Aldrich, St. Louis, MO) were diluted with probe diluent, mixed well, and stored in the dark. The final concentration of DHR was selected in the range of 100 times of dilution, the incubation time was selected as $2 \mathrm{~h}$, and the incubation was conducted at room temperature in the dark. The cells were washed with PBS. Finally, the DHR was excited at $488 \mathrm{~nm}$ and the emission was measured at $525 \mathrm{~nm}$ by fluorescence microscopy.

\section{In vivo xenograft tumor growth}

Female BALB/c nude mice of 4-5 weeks old were purchased from Beijing HFK Bioscience Co., Ltd. (Beijing, China). $1 \times 10^{7} \mathrm{NC}$ or shSeptin4 HCT116 stable cells were injected into the armpits of nude mice $(n=6)$. Tumors had fully developed by day 4 . Tumor size was measured every three days, and tumor volumes were calculated as length $\times$ width $\times$ height $\left(\mathrm{mm}^{3}\right)$. On day 28 , the mice were killed and photographed, and then the tumors were excised, weighed, and photographed.

\section{Statistical analysis}

SPSS 22.0 software (SPSS Inc, Chicago IL, U.S.) was used for data analysis. The data are expressed as mean \pm standard deviation (SD). Statistical significance was analyzed using a Student's $t$-test or a one-way analysis of variance followed by a Tukey's multiple comparisons test. Kaplan-Meier survival analysis was used to assess the association of Septin4 expression and CRC prognosis. $P<0.05$ represented statistical significance. 


\section{Results}

\section{Septin4 expression decrease with increased malignancy of colon cancer and are associated with survival outcomes}

Firstly, we examined the expression of Septin 4 in tissue specimens from 79 colon cancer patients, to elucidate the role of Septin4 in vivo. Septin4 expression and the patient clinicopathological parameters were analyzed. Table 1 shows that there was no significant difference between Septin4 expression and sex, age, histopathological TNM staging $(P>0.05)$. However, based on grade, Septin4 expression was correlated with grade I-II and III-IV $(P<0.001)$ (Table 1). Semiquantitative immunohistochemical analysis revealed a 1.6-fold higher level of Septin4 in peritumoral benign colon cancer cells when compared with colon cancer cells (Figure 1A, B; mean score 8 vs $5, P<0.001)$. Furthermore, Septin4 expression was significantly lower in advanced CRC cells (grade III-IV) (Figure. 1C, D). Next, we examined whether or not Septin4 expression was associated with prognosis of CRC. Low Septin4 expression (score $0-5)$ was associated with a significantly worse overall survival when compared to those with a high expression level (score 6-10; Figure 1E). These results indicate that low Septin4 expression is implicated in the prognosis of CRC at advanced grade.

Table 1. Relationship of Septin4 expression and clinicopathological parameters in colorectal cancer patients $(n=$ 79)

\begin{tabular}{llll}
\hline \multicolumn{4}{l}{ Septin4 immunostaining } \\
\hline Characteristic & $\mathrm{N}(41)$ & High (6-10) & \\
Gender (N) & & $\mathrm{N}(38)$ & 0.900 \\
Male & $20(48.8)$ & $18(47.4)$ & \\
Female & $21(51.2)$ & $20(52.6)$ & 0.387 \\
Age (years) & $68.902 \pm 8.9883$ & $66.947 \pm 10.9321$ & 0.001 \\
Grade & & & \\
I-II & $29(70.7)$ & $37(97.4)$ & 0.190 \\
III, III-IV & $12(29.3)$ & $1(2.6)$ & \\
Clinical stages & & & \\
I-II & $21(51.2)$ & $25(65.8)$ & \\
III-IV & $20(48.8)$ & $13(34.2)$ & \\
Lymph node metasis & & & \\
N0 & $22(53.7)$ & $26(68.4)$ & \\
N1 & $19(46.3)$ & $12(31.6)$ & \\
Distant metasis & & & \\
M0 & $41(100.0)$ & $38(100.0)$ & \\
M1 & $0(0)$ & $0(0)$ & \\
\hline
\end{tabular}

\section{Septin4 is involved in the apoptotic cell death of colon cancer cells.}

As it was revealed that Septin4 expression is correlated with grade and survival outcomes in CRC, we investigated the significance of Septin4 expression in CRC biology. The apoptosis of the human colon cancer cell line HCT116 was induced by a concentration gradient of DOX in vitro. The results showed that the apoptosis-related proteins, cleaved-PARP1 and cleaved-caspase3, were increased with the increase in DOX concentration, and reached a peak under the induction of $0.05 \mu \mathrm{mol} / \mathrm{L}$ DOX (Figure 2A, B). PCNA was also detected as an index to evaluate cell proliferation status. High level of PCNA is associated with poor prognosis in CRC patients and is a reliable and prognostic biomarker[25-27]. The expression of PCNA was decreased with increased DOX concentration, reaching the minimum at 0.05 $\mu \mathrm{mol} / \mathrm{L}$ DOX, while Septin4 was increased with the increase in DOX and reached a peak at $0.4 \mu \mathrm{mol} / \mathrm{L}$ DOX (Figure 2C, D). Therefore, we determined that $0.05 \mu \mathrm{mol} / \mathrm{L}$ DOX was the best concentration to induce apoptosis of HCT116 cells. We also detected changes in PCNA and Septin4 mRNA expression under DOX treatment. As shown in Figure S1, PCNA mRNA was significantly reduced after DOX treatment for $48 \mathrm{~h}$, while Septin 4 mRNA expression was increased. In addition, the changes in the protein level of cleaved-PARP1, cleaved-caspase3, PCNA and Septin4 was detected under time gradient conditions. PCNA expression was significantly reduced at $48 \mathrm{~h}$, while cleaved-PARP1, cleaved-caspase3, and Septin4 were increased (Figure S2). These findings demonstrated that DOX could induce the apoptosis of HCT116 cells and that Septin4 was involved in this process. Then, DHR staining was performed to detect ROS production under a DOX concentration gradient. HCT116 induced by DOX at $2 \mu \mathrm{mol} / \mathrm{L}$ showed the highest ROS production (Figure 2E, F). Similar results were observed using CCK8 to analyze the viability of cells, and under $2 \mu \mathrm{mol} / \mathrm{L}$ DOX treatment cells were almost completely dead (Figure 2G). These results indicate that Septin 4 is involved in the apoptosis process of HCT116 cells.

\section{Overexpression of Septin4 aggravated DOX-induced apoptosis of colon cancer cells}

Next, we determined the role of Septin4 in DOX-induced apoptosis of colon cancer cells. We used normal colon cancer cells and Septin4-overexpressed colon cancer cells with or without $0.05 \mu \mathrm{mol} / \mathrm{L}$ DOX to induce apoptosis. We detected the expression levels of apoptosis-related proteins cleaved-PARP1 and cleaved-caspase3 by immunoblotting. The results showed that cleaved-PARP1 (Figure 3A) and cleaved-caspase3 (Figure 3C) increased significantly in the Septin4-overexpressed colon cancer cells induced by DOX compared with the control group. Also, the expression of PCNA in the Septin4-overexpressed cells decreased significantly compared to the control group under DOX stimulation (Figure 3E). Consistent 
with these findings, ROS production evaluated by DHR staining in figure $3 \mathrm{G}$ showed a significant increase in ROS production compared with the control group under DOX induction. These findings were consistent with apoptosis rate detected by TUNEL assay (Figure S3). CCK8 analysis also demonstrated that the cell viability decreased significantly after overexpression of Septin4 was induced by DOX (Figure 3I). In conclusion, overexpression of Septin4 aggravated DOX-induced apoptosis of colon cancer cells.
A
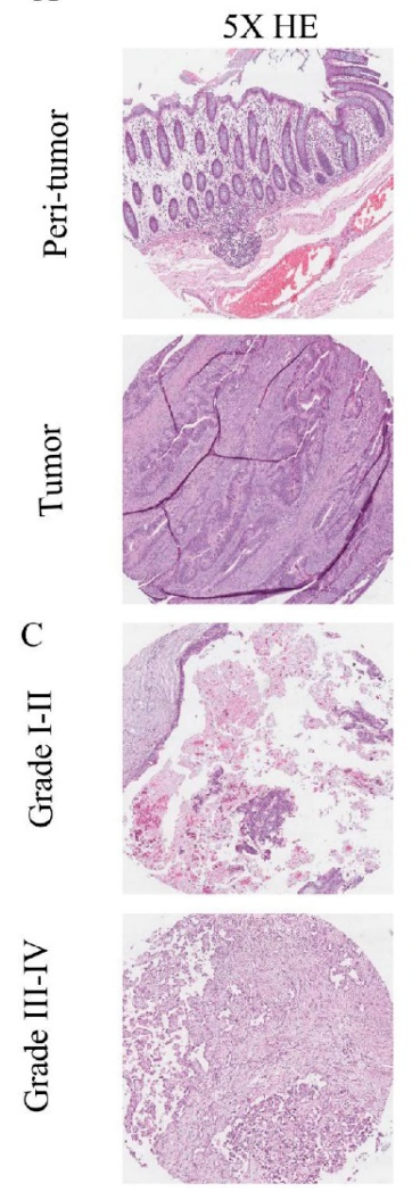

20X Septin4
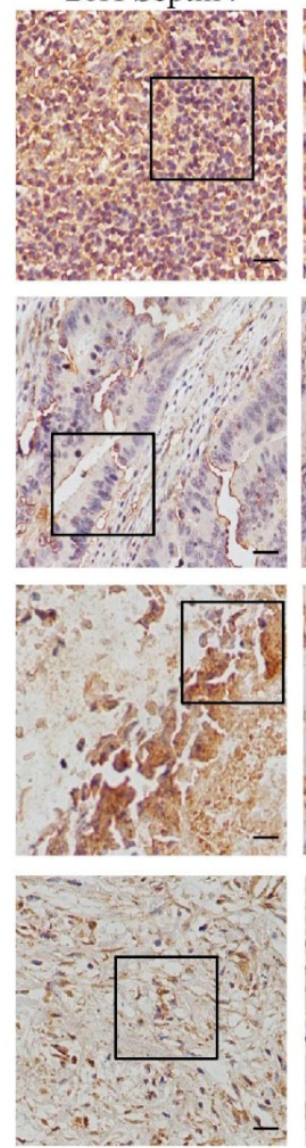

40X Septin4
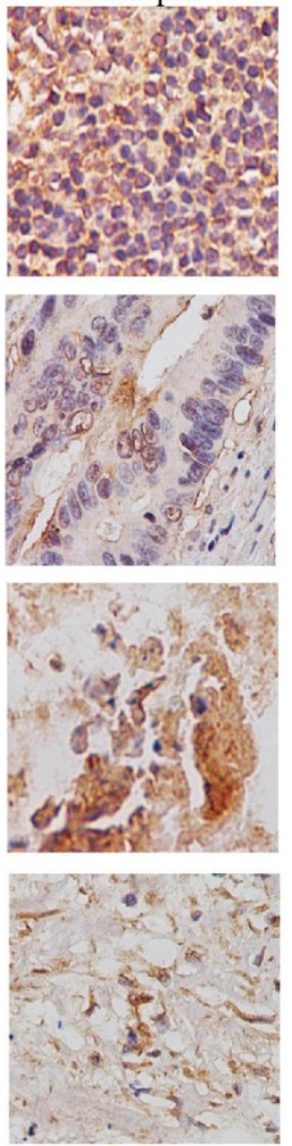

B

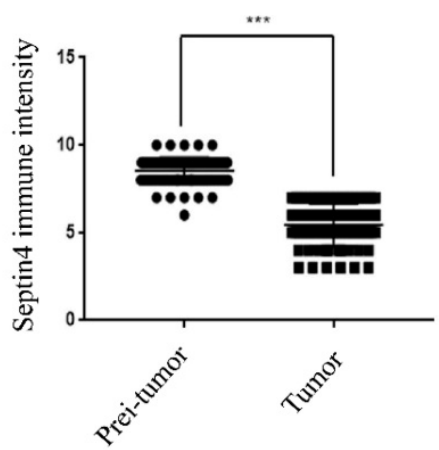

D

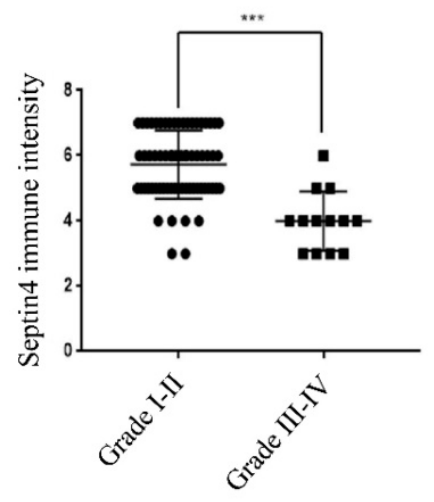

E

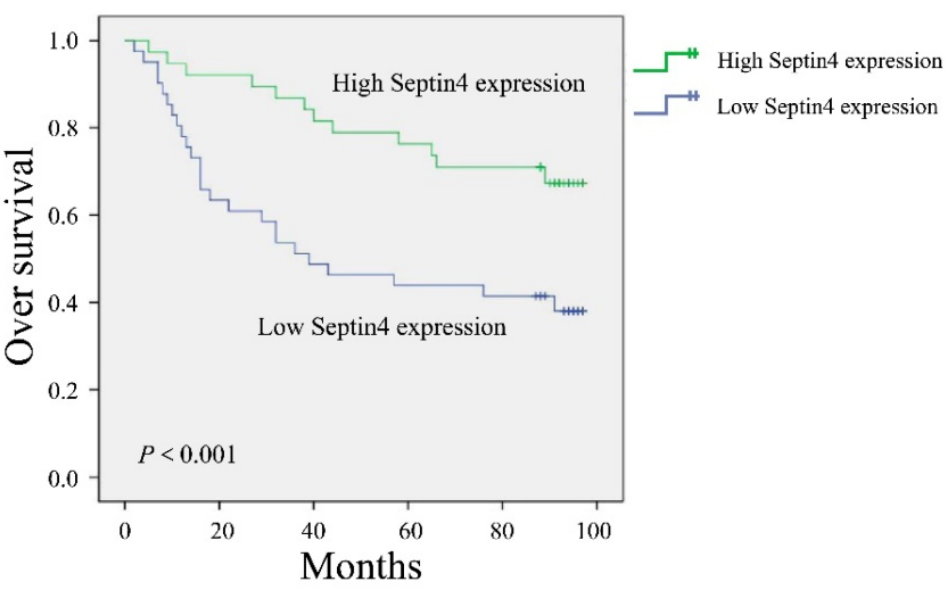

Figure 1. Septin4 expression was correlated with good prognosis in human colorectal cancer. A. Septin 4 protein expression in CRC and paired peritumoral colonic tissue $(n=79)$ was detected by immunohistochemical staining. Scale bars, $20 \mu \mathrm{m}$. B. Scores indicated Septin4 levels by a 10 -point quantification scale, data are shown as means \pm S.D., $* * * P<0.001$. C. Immunohistochemical staining of Septin 4 was displayed in clinical CRC at different grades. Scale bars, $20 \mu m$. D. Column plot analysis of Septin 4 expression in CRC samples at different grades, data are shown as means $\pm S . D$., ***P $<0.001$. E. Kaplan-Meier survival curve showing high Septin4 expression (score 6-10, $\mathrm{n}=38$ ) was associated with better overall survival compared with low Septin4 expression (score 0-5, $n=41$ ). 
A

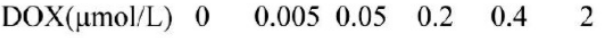

IB:Cleaved-PARP1

IB:Cleaved-caspase3

IB: $\beta$-actin

C

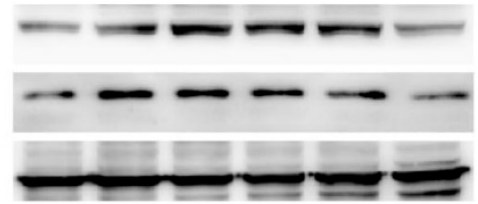

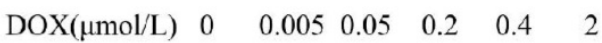

IB:PCNA

IB:Septin4

IB: $\beta$-actin

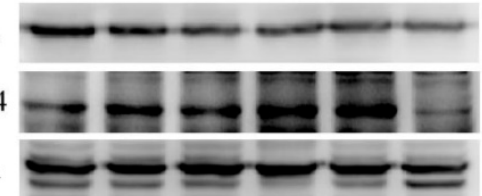

E $\operatorname{DOX}(\mu \mathrm{mol} / \mathrm{L})$

0

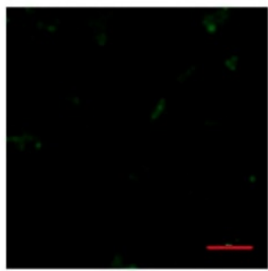

$\operatorname{DOX}(\mu \mathrm{mol} / \mathrm{L})$

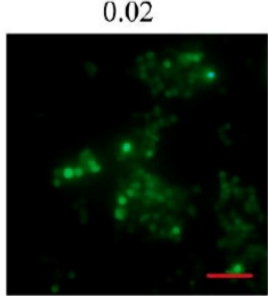

F

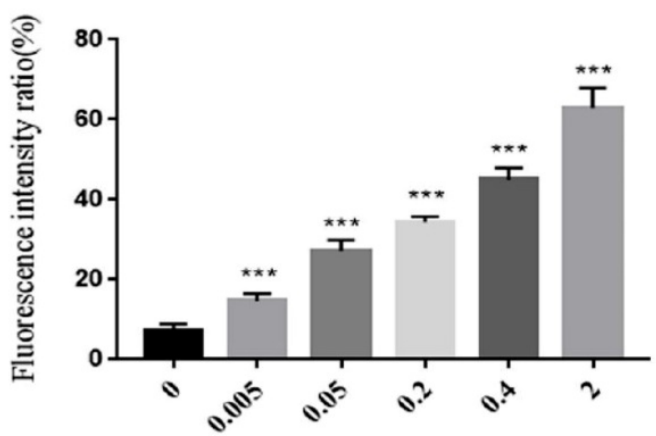

$\operatorname{Dox}(\mu \mathrm{mol} / \mathrm{L})$

0.4
B

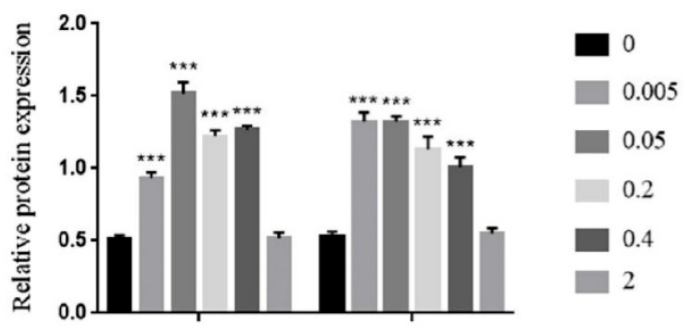

D
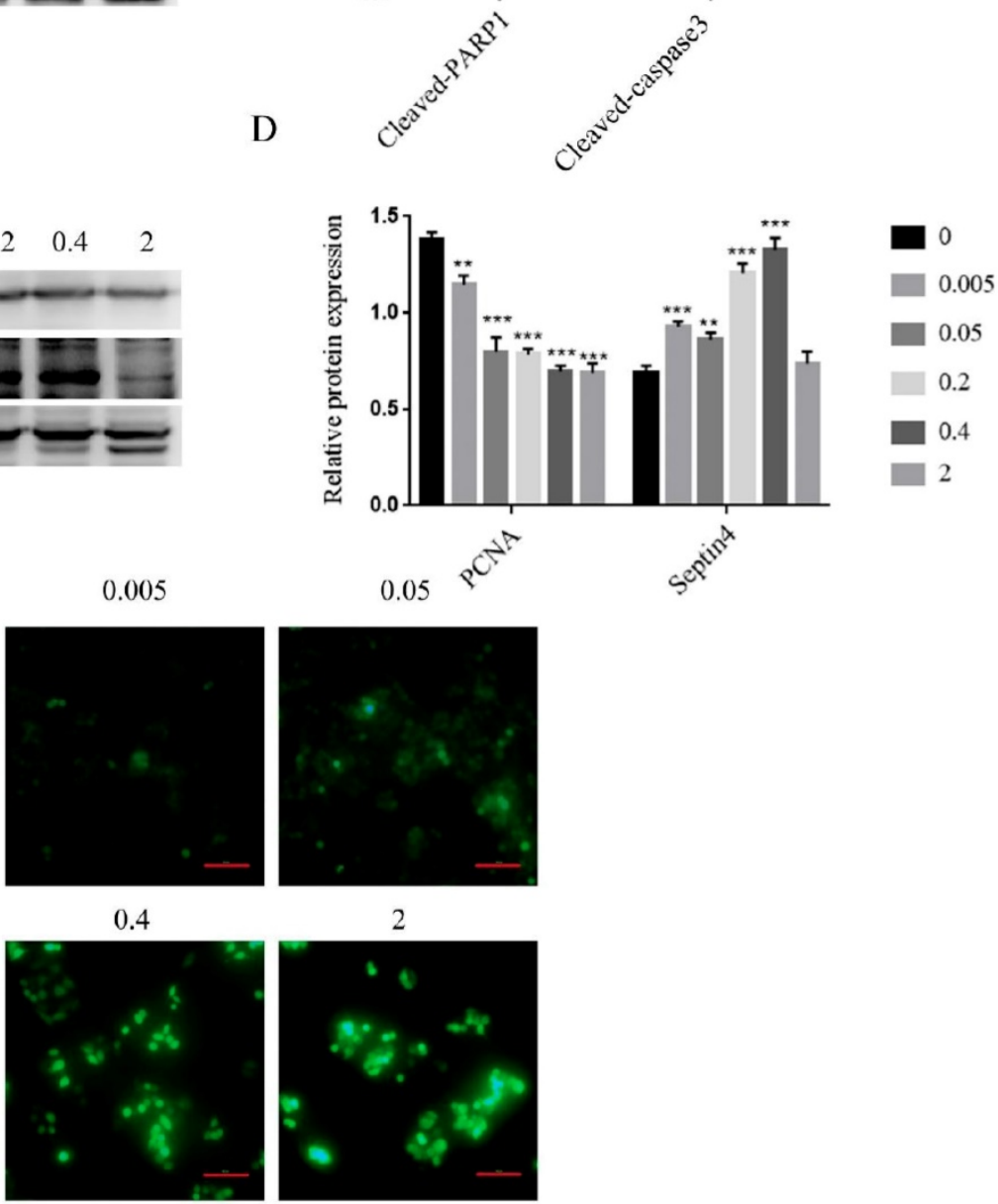

G

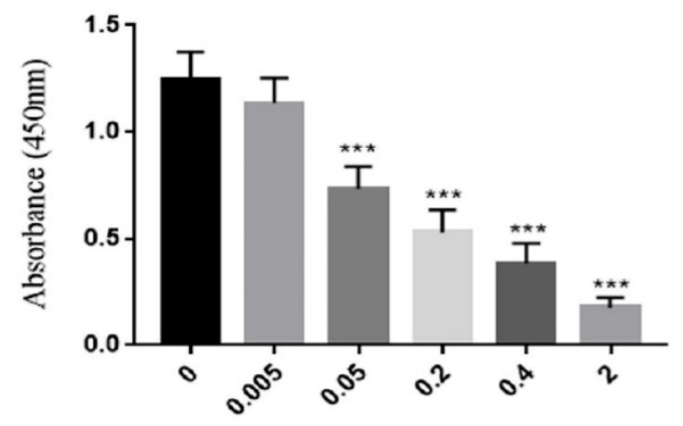

$\operatorname{Dox}(\mu \mathrm{mol} / \mathrm{L})$

Figure 2. Septin4 participated in DOX-induced apoptosis of HCT 116 cells. A. HCT1 16 cells were treated with DOX at $0,0.005,0.05,0.2,0.4$, and $2 \mu$ mol/L for $48 \mathrm{~h}$, to detect the expression of cleaved-caspase 3 and cleaved-PARPI. B. Quantification of protein expression in A were shown as the means \pm S.D., ****P<0.001 C. The expression of PCNA and Septin 4 was detected in the presence of DOX at $0,0.005,0.05,0.2,0.4$, and $2 \mu \mathrm{mol} / \mathrm{L}$ for $48 \mathrm{~h}$. D. Quantification of protein expression in $\mathrm{C}$ were shown as the means $\pm S . D$., $* * P<0.01$, $* * * P<0.001$. E. The generation of ROS was detected by $\mathrm{DHR}$ staining under the treatment of $0,0.005,0.05,0.2,0.4$, and $2 \mu \mathrm{mol} / \mathrm{L} \mathrm{DOX}$ for $48 \mathrm{~h}$. Scale bars, $100 \mu \mathrm{m}$. F. Quantitative analyses of the fluorescence intensity in E, data are shown as means $\pm S . D$., $* * * P<0.001$. G. Statistical results of CCK8 analysis of HCT116 treated with DOX at $0,0.005,0.05,0.2,0.4$, and $2 \mu \mathrm{mol} / \mathrm{L}$ for $48 \mathrm{~h}$, data are shown as means \pm S.D., $* * * P<0.001$. 
A

Flag-Septin4 $\operatorname{DOX}(0.05 \mu \mathrm{mol} / \mathrm{L})$ IB:Cleaved-PARP1 IB:Flag-Septin4 IB: $\beta$-actin

C

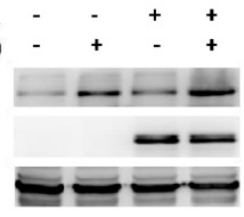

Flag-Septin DOX $(0.05 \mu \mathrm{mol} / \mathrm{L})$ IB:Cleaved-caspase 3 IB:Flag-Septin4 IB: $\beta$-actin

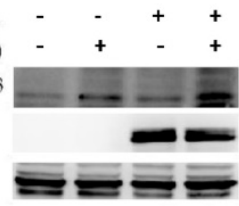

E

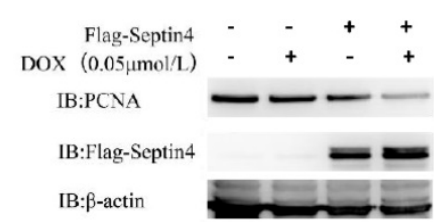

G

Flag-vector

Flag-Septin4

홍
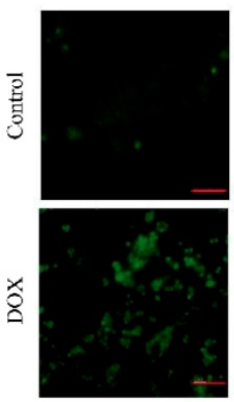

I
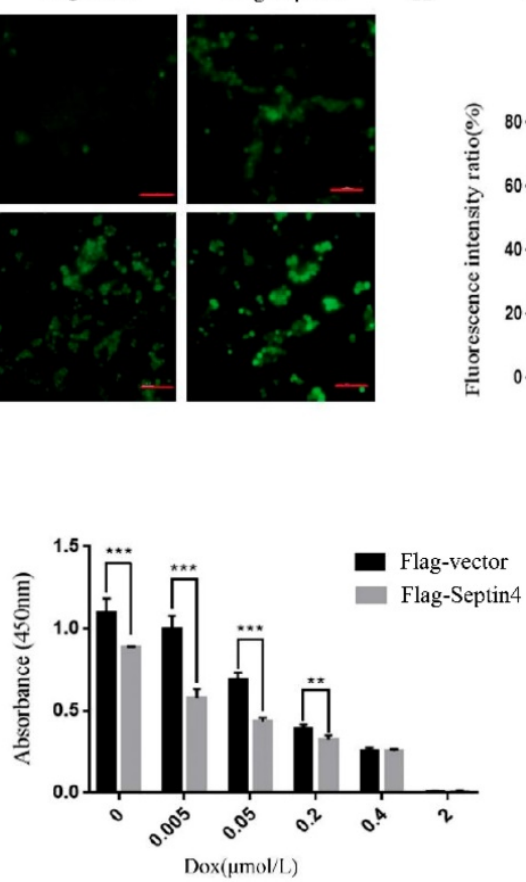

B

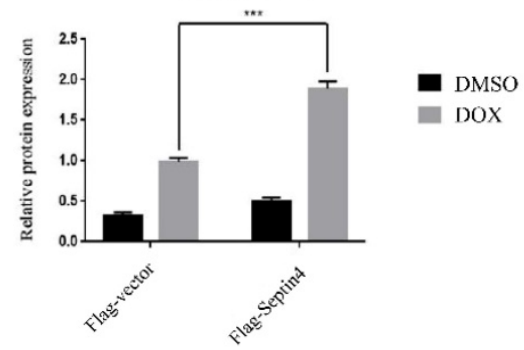

D

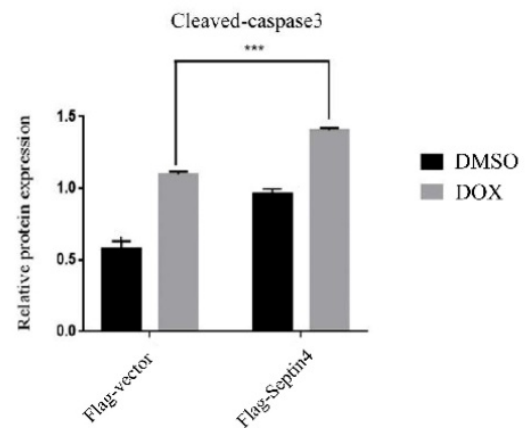

F

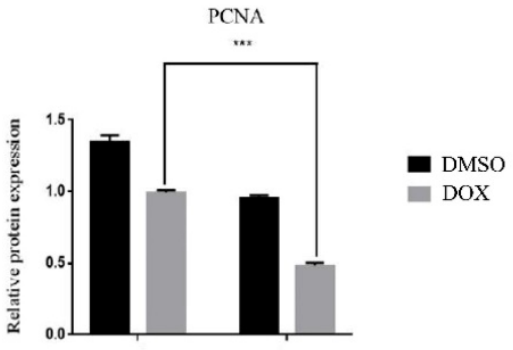

H
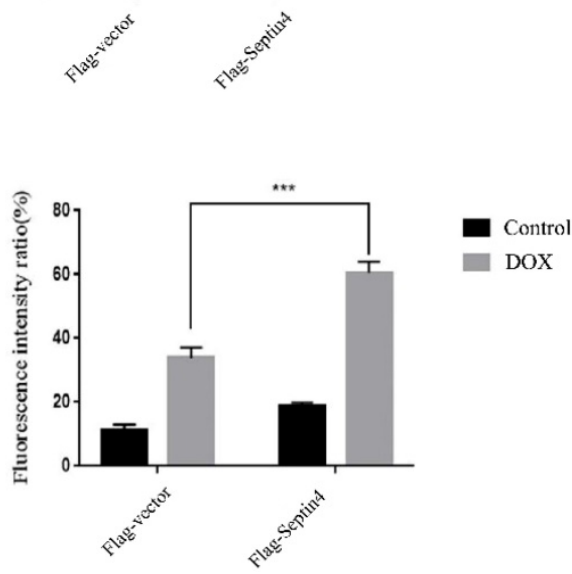

Figure 3. Overexpression of Septin4 enhanced sensitivity to DOX in colon cancer cells. A. HCT116 overexpressing Flag-Vector and Flag-Septin4 were treated with DOX at a concentration of $0.05 \mu \mathrm{mol} / \mathrm{L}$ for $48 \mathrm{~h}$ to detect the expression of cleaved-PARPI and Flag-Septin4. B. Quantitative analysis of the expression of cleaved-PARP1 in A. Data were shown as the means \pm S.D., $* * * P<0.001$. C. HCT1 16 overexpressing Flag-Vector and Flag-Septin 4 were treated with DOX at a concentration of $0.05 \mu$ mol/L for $48 \mathrm{~h}$ to detect the expression of cleaved-caspase3 and Flag-Septin4. D. Quantitative analysis of the expression of cleaved-caspase3. Data were shown as the means \pm S.D., 
$* * * P<0.001 . E$. HCT1 16 overexpressing Flag-Vector and Flag-Septin4 were treated with DOX at a concentration of $0.05 \mu \mathrm{mol} / \mathrm{L}$ for $48 \mathrm{~h}$ to detect the expression of PCNA and Flag-Septin4. F. Quantitative analysis of the expression of PCNA in E. Data were shown as the means \pm S.D., ***P<0.001. G. The generation of ROS was detected by DHR staining in HCT116 overexpressing Flag-Vector and Flag-Septin4 treated with DOX at a concentration of $0.05 \mu \mathrm{mol} / \mathrm{L}$ for $48 \mathrm{~h}$. Scale bars, $100 \mu \mathrm{m}$. $\mathbf{H}$. Quantitative analyses of the fluorescence intensity in $\mathbf{G}$. Data are shown as means \pm S.D., ${ }^{* * * P}<0.001$. I. Statistical results of CCK8 assay of HCT 116 overexpressing Flag-Vector and Flag-Septin4 under the DOX treatment at $0,0.005,0.05,0.2,0.4$, and $2 \mu \mathrm{mol} / \mathrm{L}$ for $48 \mathrm{~h}$. Data are shown as means \pm S.D., $* * P<0.01, * * * P<0.001$.

A

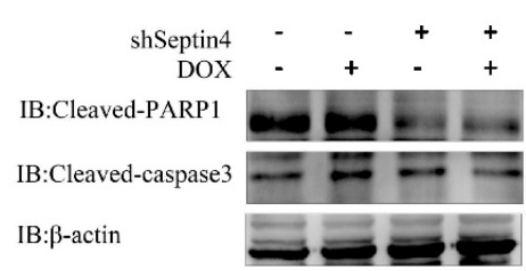

$\mathrm{C}$
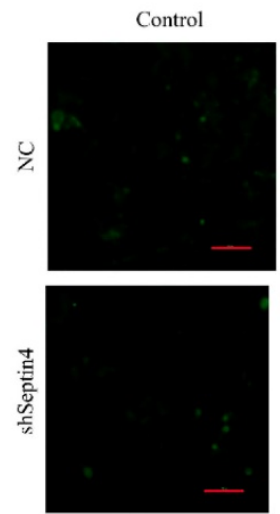

B
Cleaved-PARP1
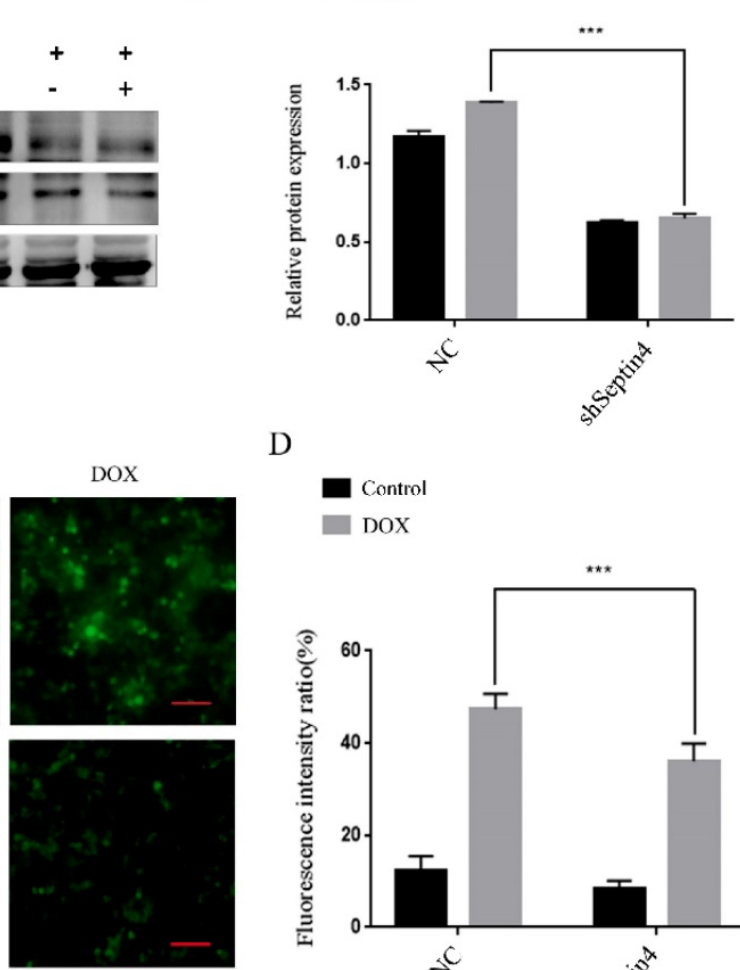

D
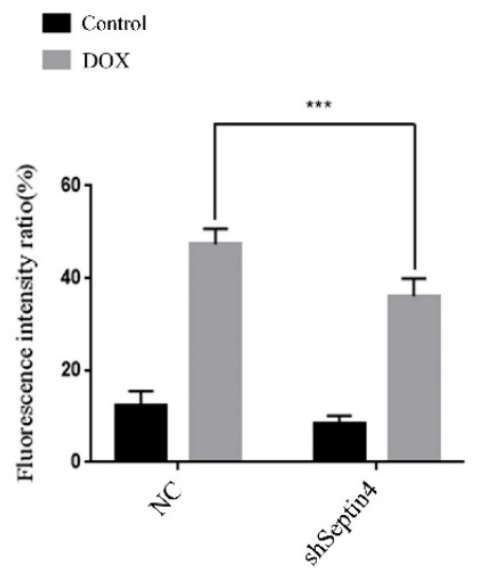

DMSO

DOX
$\mathrm{F}$

Control

DOX

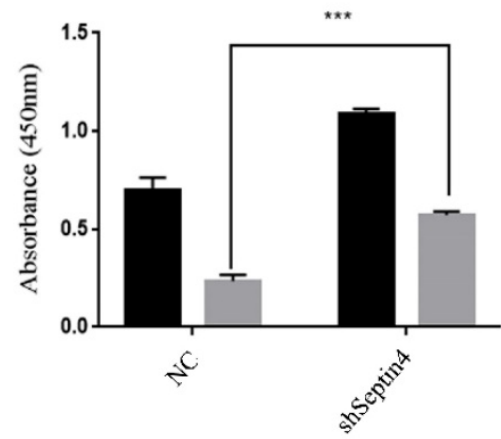

Figure 4. Depletion of Septin4 resisted DOX-induced apoptosis in HCT116 cells. A. Expression of cleaved-PARPI and cleaved-caspase3 in NC and Septin4-knockdown HCT1 16 cells were treated with DOX at $0.05 \mu \mathrm{mol} / \mathrm{L}$ for $48 \mathrm{~h}$. B. Quantitative analysis of the expression of cleaved-PARPI and cleaved-caspase3 in A. Data were shown as the means \pm S.D., $* * * P<0.001$. C. ROS staining of the NC and shSeptin 4 HCT116 cells were treated with DOX at $0.05 \mu \mathrm{mol} / \mathrm{L}$ for $48 \mathrm{~h}$. Scale bars, $100 \mu \mathrm{m}$. D. Quantitative analyses of the fluorescence intensity in C. Data are shown as means \pm S.D., $* * * P<0.001$. E. Statistical results of CCK8 analysis of NC and shSeptin4 HCT116 cells under $0.05 \mu \mathrm{mol} / \mathrm{L}$ DOX treatment for $48 \mathrm{~h}, * * * P<0.001$.

\section{Knockdown of Septin4 alleviated DOX-induced apoptosis of colon cancer cells}

To further determine the role of Septin4 in DOX-induced apoptosis of colon cancer cells, a stable knockdown of Septin4 HCT116 cell line was used to detect the expression levels of apoptosis-related proteins cleaved-PARP1 and cleaved-caspase 3 by immunoblotting with and without DOX-induced apoptosis. We found that the expression of cleaved-PARP1 and cleaved-caspase3 was decreased significantly after knockdown of Septin4 compared to NC group under DOX treatment (Figure 4A). And in the shSeptin4 cells, we could not detect a significant increase of cleaved-PARP1 and cleaved-caspase 3 after DOX treatment (Figure 4A). These results indicated that Septin4 is a key pro-apoptotic factor in DOX-induced CRC cell death. Then ROS staining was performed to evaluate the production of oxygen free radicals. The results showed that ROS production after knockdown of Septin4 decreased significantly compared to NC group under DOX treatment (Figure 4C). These findings were consistent with apoptosis rate detected by TUNEL assay (Figure S4). CCK8 analysis also showed that cell viability was significantly increased compared with the NC group under DOX treatment (Figure 4E). These results indicate that DOX-induced apoptosis is weaken by Septin4 depletion in CRC cells.

\section{Septin4 promoted apoptosis of colon cancer cells through interaction with BAX}

We next explored which protein is regulated by Septin4 to promote the apoptosis of colon cancer cells induced by DOX. BAX is an apoptotic protein with multiple $\mathrm{BH}$ domains located in the outer membrane of mitochondria and has the ability to self-assemble into homologous oligomers to disrupt MOMP. BAX exists in almost all cell types, including tumor cells. The early model of apoptosis activation suggests that 
BAX activation is regulated by the inhibitory interaction of anti-apoptotic members on the outer mitochondrial membrane [24]. We confirmed that BAX and Septin4 interacted with each other (Figure $5 \mathrm{~A}, \mathrm{C})$ and that this interaction was enhanced under DOX induction (Figure 5B, D) by endogenous immunoprecipitation. These findings suggest that Septin4 can promote the apoptosis of colon cancer cells induced by DOX through interactions with BAX.

\section{Septin4 knockdown promotes human colorectal cancer growth in vivo}

To test whether Septin4-depleted tumors are accelerated growth, a mouse-tumor model was established using NC and shSeptin4 HCT116 cells. We subcutaneously injected shSeptin4 HCT116 cells and NC cells into nude mice and analyzed tumor growth. The Septin4 deficient HCT116 cells demonstrated larger tumor size than the normal control HCT116 cells (Figure 6A, B). In addition, Figure 6 B shows that cells with Septin4-knockdown had a greater tumor growth rate than normal control HCT116 cells. Furthermore, compared with normal control cells, Septin4-knockdown HCT116 cells also had a greater tumor weight (Figure 6C, D). Collectively, our data suggested that Septin4 knockdown promoted colon tumor growth in vivo.

\section{Discussion}

In this study, for the first time, we confirmed that Septin4 expression levels were decreased with increased colon cancer grade, and patients with high expression of Septin4 had a good prognosis. We used Septin4-overexpressing and -knockdown cell lines to demonstrate Septin4 can promote the apoptosis of colon cancer cells and ROS production. Then we identified BAX as a new downstream substrate of Septin4 by immunoprecipitation. The results showed that Septin4 promoted apoptosis of colon cancer cells by binding to BAX. Then we performed tumor formation in vivo, which revealed that Septin4 knockdown accelerated subcutaneous tumor growth in nude mice. These findings may contribute to future research on the occurrence and development of CRC and provide new technical approaches for targeted treatment of CRC.

Septin4_i2 (ARTS) is an important apoptotic tumor suppressor protein encoded by SEPT4 gene. ARTS is located in the outer membrane of mitochondria and translocate to the cytoplasm after
A

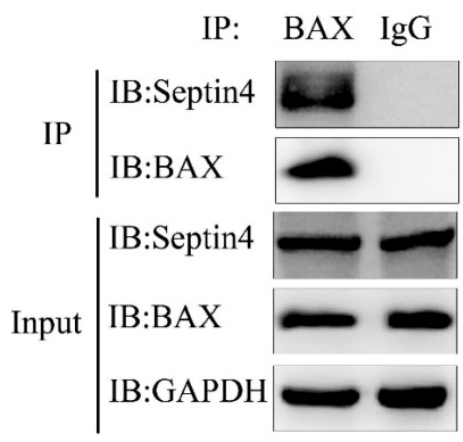

$\mathrm{C}$

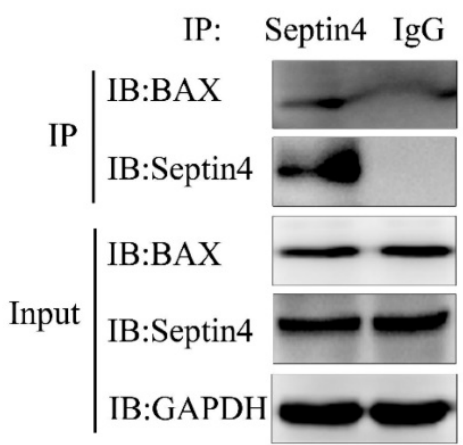

B

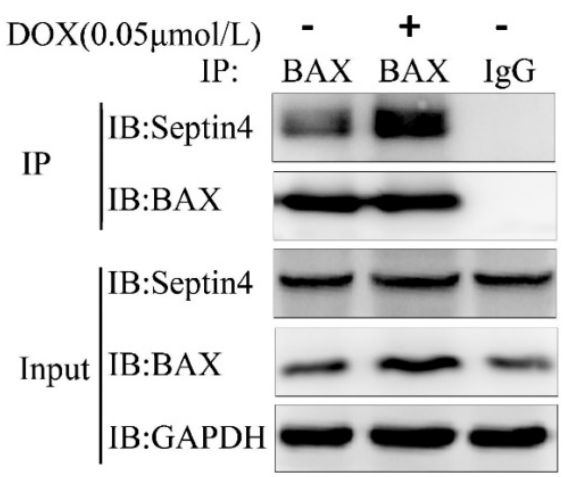

$\mathrm{D}$

$\operatorname{DOX}(0.05 \mu \mathrm{mol} / \mathrm{L}) \quad-\quad+\quad-$

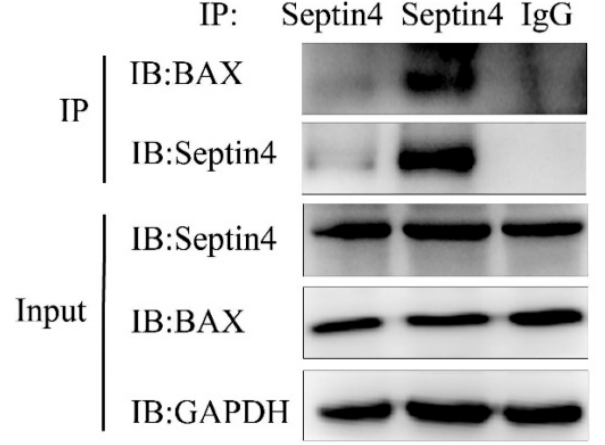

Figure 5. Septin4 promoted apoptosis of colon cancer cells through interactions with BAX. A, C. Immunoblotting with antibodies against Septin4 and BAX following immunoprecipitation using control species matched IgG and anti-BAX antibody (A) or anti-Septin4 antibody (C) in HCT116 cells. B, D. Immunoblotting with antibodies against Septin4 and BAX following immunoprecipitation using control species matched IgG and anti-BAX antibody (B) or anti-Septin4 antibody (D) in HCT116 cells with or without $0.05 \mu \mathrm{mol} / \mathrm{L}$ DOX treatment for $48 \mathrm{~h}$. 
receiving apoptosis-related stimulation. There it can inhibit caspases by mediating the degradation of XIAP to promote caspase activation and apoptosis [15, 28]. Previous research has showed that the mice without Sept4/ARTS gene has significantly improved wound healing and hair follicle regeneration, revealing that ARTS can promote skin wound healing by regulating hair follicle stem cell apoptosis [29]. In addition, the absence of Sept4/ARTS gene can also increase the number of hematopoietic stem cells and progenitor cells, increase XIAP levels, enhance apoptosis, and accelerate tumor development [18]. It is worth noting that the expression of ARTS is often lost in human leukemia, indicating that ARTS it may have a role in tumor inhibition [19]. Therefore, we speculate that in the development of colon cancer, Septin4 may also exhibit a similar effect of inhibiting tumor growth. It has been reported that SEPT4 gene expression is decreased in up to 11 tumor types, including central nervous system tumors, breast cancer, cervical cancer, liver cancer, lung cancer, and melanoma. Moreover, the difference in Septin4 gene expression is related to tumor grade, stage, and prognosis. By comparing the immunostaining of colorectal cancer and its adjacent tissues, we found that Septin4 protein levels in tumor tissues were significantly lower than those in the adjacent tissues (Figure 1A, B), suggesting that the lack of Septin4 in colon cancer cells may be one of the critical factors in promoting the proliferation of cancer cells. This also suggested that Septin4 may act as a potential oncogene or tumor suppressor gene in the development of some cancer types. With colon cancer progression, we found that the expression of Septin 4 decreased (Table 1, Figure 1C and D), which suggested that Septin4 has an important role in the inhibition of colon cancer development.
A
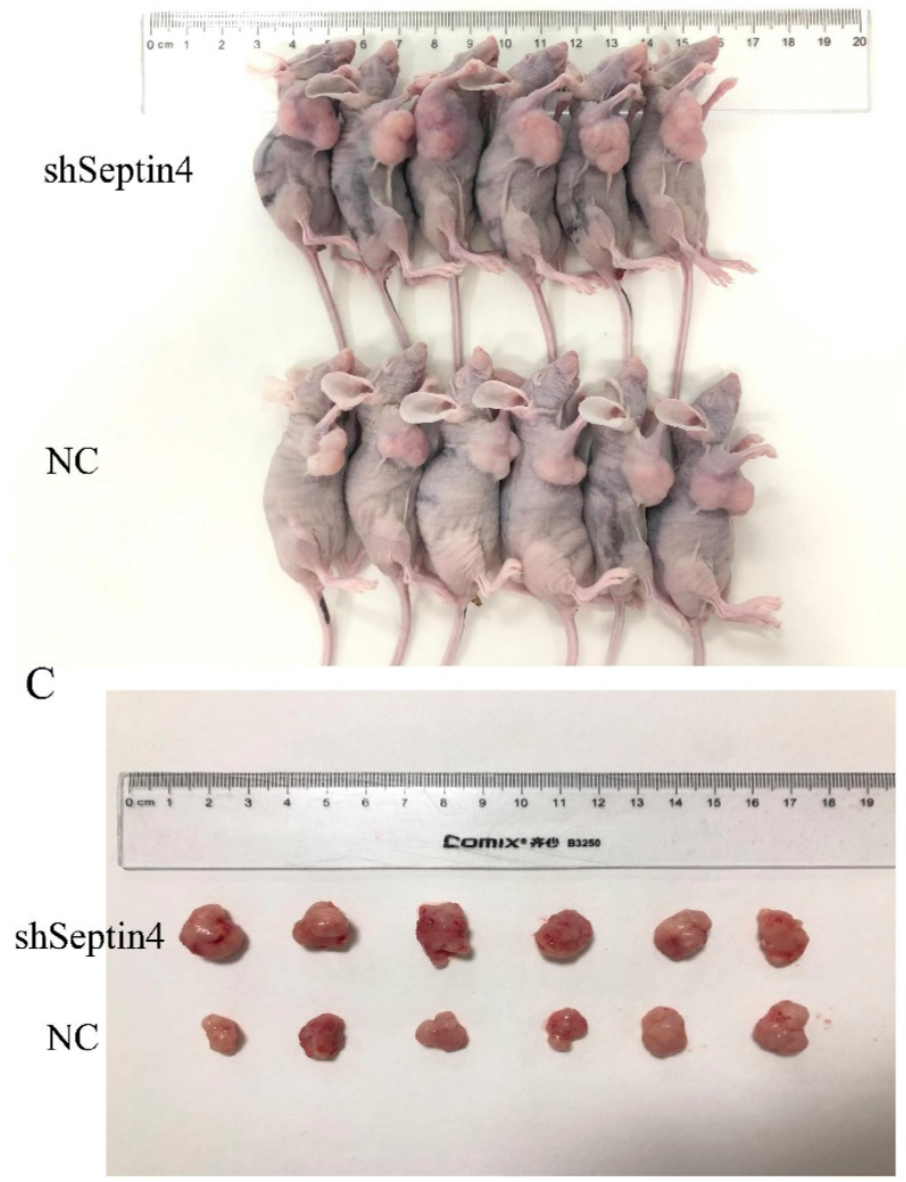

B

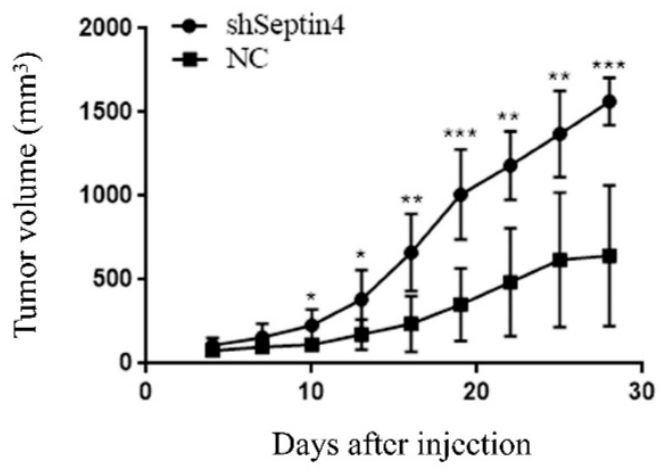

$\mathrm{D}$

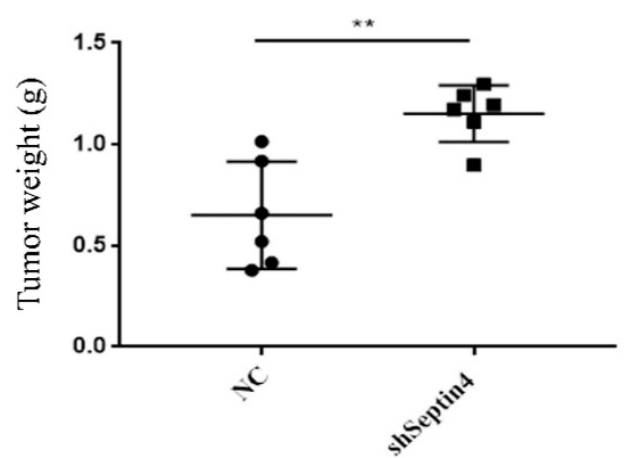

Figure 6. Suppression of Septin4 enhances human colorectal cancer growth in vivo. A. Xenografts was generated using HCT116 cells with stable Septin4 knockdown and normal control. Mice were killed and photographed at day 28. B. Tumor size was measured every 3 days and tumor volume was analyzed. Septin4-knockdown (shSeptin4) or control (NC) HCT1 16 cells were used in this analysis. The means \pm S.D. of tumor volume are shown. $* P<0.05 ; * * P<0.01$, $* * * P<0.001$. C. Macroscopic images of transplanted tumors excised at day 28. D. The tumor weight was calculated on day 28. Data are shown as mean \pm SD $(n=6)$. $* * P<0.01$. 
Some studies have shown that ARTS is deficient in all patients with acute lymphoblastic leukemia, and the degree of deficiency is significantly related to the malignant state of the disease. Leukemia cells lacking ARTS are resistant to cytosine arabinoside-induced apoptosis [19]. However, after ARTS was transfected into these cells, they recovered their sensitivity to chemotherapy. To investigate whether Septin4 displays similar regulatory effects on the proliferation and apoptosis of colon cancer cells, we overexpressed Septin4 in HCT116 cells (Figure 3A). At the same time, we treated HCT116 cells with DOX, a DNA damaging agent that can inhibit proliferation and induce apoptosis by promoting the production of ROS. We examined the apoptosis-related proteins cleavedPARP1 and cleaved-caspase 3 by western blotting, ROS production, and cell viability by CCK8 assay, and confirmed that Septin 4 promoted the process of apoptosis (Figure 3, S3). After DOX stimulation, the expression of cleaved-PARP1 and cleaved-caspase 3 were increased, the production of ROS was increased significantly, and cell viability was decreased (Figure 3). Together, these results show that Septin 4 can improve the sensitivity of HCT116 cells to DOX cytotoxic.

The location of Septin 4 in the outer membrane of mitochondria is critical to its role in promoting apoptosis. The abnormal size of mitochondrion in spermatozoa with deletion of Sept4 gene indicates the role of Sept4 in mitosis and caspase-mediated cytoplasmic removal during spermatogenesis [30]. In the mitochondrial apoptotic pathway, the release of apoptotic factors (including cytochrome $c$ and Smac/Diablo (SMAC)) from the mitochondrial inter membrane space to the cytoplasm promotes caspase activation [23]. After stimulation with apoptosis signals, Septin4 can transfer from the mitochondrial membrane to the cytoplasm, combine with XIAP, inhibit XIAP activity, and promote caspase activation to induce apoptosis [14]. However, it is still unclear whether Septin4 can directly bind to mitochondrial membrane proteins to cause MOMP and promote the release of cytochrome $c$. Effective apoptosis requires BAX-/BAK-mediated increased MOMP [31]. To activate MOMP, $\mathrm{BH} 3$ domain protein is required to bind and inhibit the pro-survival $\mathrm{Bcl}-2$ family members, or directly bind and activate BAX and BAK, so as to increase MOMP [31, 32]. As Septin4 shows a clear apoptotic effect in colon cancer cells (Figure 3 and 4), we speculate that mitochondrial membrane proteins may directly bind to it in addition to XIAP. Recent studies have reported that ARTS can combine with BCL-2 to form a XIAP-ARTS-Bcl-2 complex. Through the E3 ubiquitin ligase function of XIAP, the complex can mediate the degradation of Bcl-2 through the ubiquitin proteasome pathway to promote apoptosis [16]. To clarify the mechanism of Septin4 in promoting the apoptosis of tumor cells, we found that Septin4 can interact with BAX and enhance this interaction following stimulation with DOX (Figure 5). This result revealed that Septin4 may increase MOMP, accelerate the release of cytochrome $c$, and promote apoptosis by directly combining with the mitochondrial membrane protein BAX. These results suggest that the interaction between Septin 4 and BAX may have a critical role in inhibiting the development of colon cancer. This new mechanism of Septin4 provides a theoretical basis for its potential as a new target of colon cancer treatment. Finally, to verify these identified mechanisms in vivo, we subcutaneously injected HCT116 Septin4-knockdown or control cells into nude mice. The results showed that the volume of subcutaneous in situ tumors without Septin4 gene was significantly larger than those of the control group (Figure 6). Together, these findings indicated that Septin4 could inhibit the proliferation of tumor cells.

Surgery, chemotherapy, and radiotherapy are still the most common treatments for colorectal cancer [33]. However, the effects of these traditional therapies are still not as good as expected. Therefore, it is imperative to identify a more effective treatment for colorectal cancer. Targeted therapies showing various advantages stand out among the current clinical treatment approaches for cancer and will be the focus of future drug development. Cetuximab and panitumumab, which are both monoclonal antibodies against EGFR, have been put into clinical application in the treatment of CRC [34, 35]. EGFR is highly expressed in $60 \%-70 \%$ of CRC patients who can benefit from EGFR-targeted therapy [36, 37]. However, these targeted cancer drugs are ineffective for patients with low EGFR expression or who have mutations in the extracellular domain of EGFR, and thus it is necessary to identify new therapeutic targets in addition to EGFR. Our study revealed for the first time that BAX, a new interacting protein of Septin4, has a critical role in mitochondrial apoptosis, suggesting that Septin4 may participate in controlling MOMP and promote apoptosis. However, this study also has some limitations. The correlation between Septin 4 and CRC invasion and metastasis needs to be further clarified. In future experiments, we will further explore the role of Septin4 in CRC resistance.

In conclusion, we revealed low Septin4 expression in colon cancer. Overexpression of Septin 4 can increase the chemosensitivity of colon cancer and inhibit its progression. In addition, Septin 4 and BAX interact to regulate the apoptosis of colon cancer cells. 
These findings suggest that the Septin4/BAX pathway may be a new target of CRC treatment.

\section{Supplementary Material}

Supplementary materials and methods, figures. http://www.ijbs.com/v16p1917s1.pdf

\section{Acknowledgments}

This work was supported by National Key R\&D Program of China (2016YFC1302400). The Ministry of education innovation team development plan to Liu Cao (IRT_17R107\&IRT13101). Key project of the National Natural Science Foundation to Liu Cao (81130042, 31171323, 81770001, 2015225003) National Science Foundation of China to Xiaoyu Song (31300963, LFWK201725), Hao Feng (81800839), Qiqiang Guo (81502400), Yi Guan (81502447) and Fei Yi (81502414). Liaoning education department general project to Hongde Xu (LK201627).

\section{Competing Interests}

The authors have declared that no competing interest exists.

\section{References}

1. Kuipers EJ, Grady WM, Lieberman D, Seufferlein T, Sung JJ, Boelens PG, et al. Colorectal cancer. Nature reviews Disease primers. 2015; 1: 15065.

2. Fleming M, Ravula S, Tatishchev SF, Wang HL. Colorectal carcinoma: Pathologic aspects. Journal of gastrointestinal oncology. 2012; 3: 153-73.

3. Brenner $\mathrm{H}$, Stock $\mathrm{C}$, Hoffmeister M. Effect of screening sigmoidoscopy and screening colonoscopy on colorectal cancer incidence and mortality: systematic review and meta-analysis of randomised controlled trials and observational studies. Bmj. 2014; 348: g2467.

4. Malin JZ, Shaham S. Cell Death in C. elegans Development. Current topics in developmental biology. 2015; 114: 1-42.

5. Pastukhov VA. [The effects of administering kynurenine into the dorsal hippocampus area in dogs]. Fiziologicheskii zhurnal SSSR imeni I M Sechenova. 1989; 75: 1267-9.

6. Fuchs Y, Steller H. Programmed cell death in animal development and disease. Cell. 2011; 147: 742-58.

7. Boyce M, Degterev A, Yuan J. Caspases: an ancient cellular sword of Damocles. Cell death and differentiation. 2004; 11: 29-37.

8. Gyrd-Hansen M, Meier P. IAPs: from caspase inhibitors to modulators of NF-kappaB, inflammation and cancer. Nature reviews Cancer. 2010; 10: $561-74$

9. Du C, Fang M, Li Y, Li L, Wang X. Smac, a mitochondrial protein that promotes cytochrome c-dependent caspase activation by eliminating IAP inhibition. Cell. 2000; 102: 33-42.

10. Verhagen AM, Ekert PG, Pakusch M, Silke J, Connolly LM, Reid GE, et al. Identification of DIABLO, a mammalian protein that promotes apoptosis by binding to and antagonizing IAP proteins. Cell. 2000; 102: 43-53.

11. Gottfried Y, Rotem A, Lotan R, Steller H, Larisch S. The mitochondrial ARTS protein promotes apoptosis through targeting XIAP. The EMBO journal. 2004; 23: $1627-35$.

12. Larisch S. The ARTS connection: role of ARTS in apoptosis and cancer. Cell cycle. 2004; 3: 1021-3.

13. Larisch S, Yi Y, Lotan R, Kerner H, Eimerl S, Tony Parks W, et al. A novel mitochondrial septin-like protein, ARTS, mediates apoptosis dependent on its P-loop motif. Nature cell biology. 2000; 2: 915-21.

14. Edison N, Zuri D, Maniv I, Bornstein B, Lev T, Gottfried Y, et al. The IAP-antagonist ARTS initiates caspase activation upstream of cytochrome $\mathrm{C}$ and SMAC/Diablo. Cell death and differentiation. 2012; 19: 356-68.

15. Bornstein B, Gottfried Y, Edison N, Shekhtman A, Lev T, Glaser F, et al. ARTS binds to a distinct domain in XIAP-BIR3 and promotes apoptosis by a mechanism that is different from other IAP-antagonists. Apoptosis : an international journal on programmed cell death. 2011; 16: 869-81.

16. Edison N, Curtz Y, Paland N, Mamriev D, Chorubczyk N, Haviv-Reingewertz T, et al. Degradation of Bcl-2 by XIAP and ARTS Promotes Apoptosis. Cell reports. 2017; 21: 442-54

17. Hall PA, Russell SE. The pathobiology of the septin gene family. The Journal of pathology. 2004; 204: 489-505.
18. Garcia-Fernandez M, Kissel $\mathrm{H}$, Brown $\mathrm{S}$, Gorenc $\mathrm{T}$, Schile AJ, Rafii $\mathrm{S}$, et al. Sept4/ARTS is required for stem cell apoptosis and tumor suppression. Genes \& development. 2010; 24: 2282-93.

19. Elhasid R, Sahar D, Merling A, Zivony Y, Rotem A, Ben-Arush M, et al. Mitochondrial pro-apoptotic ARTS protein is lost in the majority of acute lymphoblastic leukemia patients. Oncogene. 2004; 23: 5468-75.

20. Koren E, Yosefzon Y, Ankawa R, Soteriou D, Jacob A, Nevelsky A, et al. ARTS mediates apoptosis and regeneration of the intestinal stem cell niche. Nature communications. 2018; 9: 4582.

21. Angelis D, Spiliotis ET. Septin Mutations in Human Cancers. Frontiers in cell and developmental biology. 2016; 4: 122.

22. Souers AJ, Leverson JD, Boghaert ER, Ackler SL, Catron ND, Chen J, et al. ABT-199, a potent and selective BCL-2 inhibitor, achieves antitumor activity while sparing platelets. Nature medicine. 2013; 19: 202-8.

23. Green DR, Kroemer G. The pathophysiology of mitochondrial cell death. Science. 2004; 305: 626-9.

24. Chen L, Willis SN, Wei A, Smith BJ, Fletcher JI, Hinds MG, et al. Differential targeting of prosurvival $\mathrm{Bcl}-2$ proteins by their $\mathrm{BH} 3$-only ligands allows complementary apoptotic function. Molecular cell. 2005; 17: 393-403.

25. Zhou H, Huang T, Xiong Y, Peng L, Wang R, Zhang GJ. The prognostic value of proliferating cell nuclear antigen expression in colorectal cancer: A meta-analysis. Medicine. 2018; 97: e13752.

26. Nakamura T, Tabuchi $Y$, Nakae S, Ohno M, Saitoh Y. Serum carcinoembryonic antigen levels and proliferating cell nuclear antigen labeling index for patients with colorectal carcinoma. Correlation with tumor progression and survival. Cancer. 1996; 77: 1741-6.

27. Paradiso A, Rabinovich M, Vallejo C, Machiavelli M, Romero A, Perez J, et al. p53 and PCNA expression in advanced colorectal cancer: response to chemotherapy and long-term prognosis. International journal of cancer. 1996; 69: 437-41.

28. Garrison JB, Correa RG, Gerlic M, Yip KW, Krieg A, Tamble CM, et al. ARTS and Siah collaborate in a pathway for XIAP degradation. Molecular cell. 2011; 41: 107-16.

29. Fuchs Y, Brown S, Gorenc T, Rodriguez J, Fuchs E, Steller H. Sept4/ARTS regulates stem cell apoptosis and skin regeneration. Science. 2013; 341: 286-9.

30. Kissel H, Georgescu MM, Larisch S, Manova K, Hunnicutt GR, Steller H. The Sept4 septin locus is required for sperm terminal differentiation in mice. Developmental cell. 2005; 8: 353-64.

31. Wei MC, Zong WX, Cheng EH, Lindsten T, Panoutsakopoulou V, Ross AJ, et al. Proapoptotic BAX and BAK: a requisite gateway to mitochondrial dysfunction and death. Science. 2001; 292: 727-30.

32. Shamas-Din A, Brahmbhatt H, Leber B, Andrews DW. BH3-only proteins: Orchestrators of apoptosis. Biochimica et biophysica acta. 2011; 1813: 508-20.

33. Cunningham D, Atkin W, Lenz HJ, Lynch HT, Minsky B, Nordlinger B, et al. Colorectal cancer. Lancet. 2010; 375: 1030-47.

34. Jonker DJ, O'Callaghan CJ, Karapetis CS, Zalcberg JR, Tu D, Au HJ, et al. Cetuximab for the treatment of colorectal cancer. The New England journal of medicine. 2007; 357: 2040-8

35. Sartore-Bianchi A, Moroni M, Veronese S, Carnaghi C, Bajetta E, Luppi G, et al. Epidermal growth factor receptor gene copy number and clinical outcome of metastatic colorectal cancer treated with panitumumab. Journal of clinical oncology : official journal of the American Society of Clinical Oncology. 2007; 25: 3238-45.

36. Del Vecchio Blanco G, Paoluzi OA, Sileri P, Rossi P, Sica G, Pallone F. Familial colorectal cancer screening: When and what to do? World journal of gastroenterology. 2015; 21: 7944-53.

37. Jonker DJ, Karapetis CS, Harbison C, O'Callaghan CJ, Tu D, Simes RJ, et al. Epiregulin gene expression as a biomarker of benefit from cetuximab in the treatment of advanced colorectal cancer. British journal of cancer. 2014; 110: 648-55. 